\title{
BM] Global Health Research for Health Justice: an ethical framework linking global health research to health equity
}

\author{
Bridget Pratt
}

To cite: Pratt B. Research for Health Justice: an ethical framework linking global health research to health equity. BMJ Global Health 2021;6:e002921. doi:10.1136/ bmjgh-2020-002921

Handling editor Stephanie M Topp

Received 15 May 2020

Revised 13 November 2020

Accepted 21 November 2020

\section{Check for updates}

(c) Author(s) (or their employer(s)) 2021. Re-use permitted under CC BY-NC. No commercial re-use. See rights and permissions. Published by BMJ.

School of Population and Global Health, University of Melbourne, Carlton, Victoria, Australia

Correspondence to Dr Bridget Pratt; bridget.pratt@unimelb.edu.au

\section{ABSTRACT}

Global health research should generate new knowledge to improve the health and well-being of those considered disadvantaged and marginalised. This goal motivates much of the global health research being undertaken today. Yet simply funding and conducting global health research will not necessarily generate the knowledge needed to help reduce health disparities between and within countries. Global health research grants programmes and projects must be structured in a particular way to generate that type of information. But how exactly should they be designed to do so? Through a programme of ethics research starting in 2009 , an ethical framework called Research for Health Justice was developed that provides guidance to global health researchers and funders on how to design research projects and grants programmes to promote global health equity. It provides guidance on, for example, what research populations and questions ought to be selected, what research capacity strengthening ought to be performed and what post-study benefits ought to be provided. This paper describes how the 'research for health justice' framework was generated and pulls together a body of work spanning the last decade to provide a comprehensive and up-to-date version of its guidance.

\section{INTRODUCTION}

As a matter of health and social justice, bioethicists have argued that global health research should generate new knowledge to improve the health and well-being of those considered disadvantaged and marginalised, foster their participation in decision-making about its conduct and build research capacity in lowand middle-income countries (LMICs). ${ }^{1-3}$ Here, global health research is defined as research focussed on health problems typically (but not exclusively) experienced in LMICs. It encompasses research with groups considered marginalised or vulnerable in high-income countries (HICs) as well as research in LMICs. Theories of justice from political philosophy provide grounds for the claim that global health research should contribute to reducing health disparities between and within countries. ${ }^{4}$

\section{Summary box}

Simply funding and undertaking global health research will not necessarily generate the knowledge needed to help reduce health disparities between and within countries.

- Drawing on the rich justice literature from political philosophy and case studies of global health research and funding practice, the Research for Health Justice framework has been developed.

- The framework offers ethical guidance to global health researchers and funders on how to design research projects and grants programmes to promote global health equity.

- It provides guidance on the following domains

- Selecting research populations.

- Selecting research topics and questions.

- Developing research capacity.

- Providing ancillary care.

- Promoting knowledge translation.

This is consistent with positions adopted by the Commission on Health Research for Development, at ministerial summits on health research and by the WHO. ${ }^{25-7}$ In 1990, for example, the Commission on Health Research for Development identified international health research partnerships as a 'powerful tool' to reduce health inequities between and within countries. ${ }^{8}$ Helping improve healthcare and systems for those considered disadvantaged and marginalised is an important value motivating much global health research today. Over the past 30 years, there has been an increase in funding and conduct of global health research that addresses diseases and health system problems experienced in LMICs. ${ }^{9}$

Justice, understood as advancing equity, is then a key guiding value for global health research. Theory and practice both strongly connect global health research to reducing global health disparities. Yet simply undertaking global health research will not necessarily generate the knowledge needed to help 
improve healthcare and systems for those considered disadvantaged and marginalised. Global health research grants programmes and projects must be structured in a particular way to generate that type of information. But how exactly should they be designed to do so?

Ethical guidance is lacking on what form of global health research is required to promote global health equity: in terms of its research populations, research questions, capacity development and post-study benefits. As such, a programme of ethics research was initiated in 2009 to develop an ethical framework to fill this gap. That work is part of broader bioethics agenda of equity and population health. ${ }^{10}{ }^{11}$ In 2000 , prominent bioethicists Solomon Benatar and Peter A Singer argued that "a new, proactive research ethics... must ultimately be concerned with reducing inequities in global health and achieving justice in health research and healthcare" (Benatar and Singer, p826). ${ }^{12}$ Their call to expand the scope of research ethics was reiterated ${ }^{1213}$ and motivated the scholarship described in this paper.

Through the programme of ethics research, an ethical framework called Research for Health Justice was developed. The framework offers ethical guidance to global health researchers and funders on how to design research projects and grants programmes to promote global health equity. This paper describes how the 'research for health justice' framework was generated and pulls together a body of conceptual and empirical work spanning the last decade to provide a comprehensive and up-to-date version of its guidance. The framework's guidance for researchers and funders is presented in tables 1 and 2, respectively. This is to provide them with the guidance in a format that is easy to follow and use in their practice.

The framework's guidance differs from the justice requirements articulated in international research ethics guidelines. ${ }^{14}$ This reflects the fact that Research for Health Justice and international guidelines are intended to address different objectives-namely, justice at the macro-level (reduction of global health disparities) and justice at the micro-level (distributive justice in the context of single trials), respectively. Linking global health research to global health equity entails different ethical requirements than achieving a fair balance of benefits and burdens in individual global health research projects. ${ }^{14}$

\section{DEVELOPING THE RESEARCH FOR HEALTH JUSTICE FRAMEWORK}

The methodological approach employed to develop the Research for Health Justice framework is called reflective equilibrium. Traditionally, reflective equilibrium entails working back and forth between theoretical considerations (intuitions, moral principles, theories) and empirical facts/information reported in the literature, testing existing theoretical considerations against new ones or newly reported empirical knowledge, revising and refining until coherence is achieved. ${ }^{15}$ Reflective equilibrium as a methodology in empirical work, despite using different tools and a wider set of judgements, is continuous with reflective equilibrium in conceptual work. In empirical ethics research, reflective equilibrium entails testing theoretical considerations against information gathered from practice-namely, the considered judgements of people who are involved the practice-under-study—using empirical methods (eg, interviews, surveys, case studies). ${ }^{16} 17$ That approach was used in this project and the considered judgements it used were those of people involved in global health research: research funders, academic researchers, ethicists, community engagement practitioners, health provider research partners, community organisation research partners, study participants and people with lived experience and members of the public who had been engaged in health research.

The empirical ethics approach to reflective equilibrium constitutes a robust methodological option for developing ethical guidance informed by both theory and practice. ${ }^{17}$ The resultant guidance reflects conceptual coherence by adapting conceptual analysis in light of empirical evidence, and, where appropriate, using social and ethical theory to challenge the intuitions evidenced in the empirical data. ${ }^{18}$ To derive the Research for Health Justice framework, three cycles of reflective equilibrium were undertaken and are described below. The case studies discussed in these cycles were approved by ethics committees at research institutions in Australia, Thailand, the UK, USA, Uganda, India and the Philippines. (In Cycle 1, the Shoklo Malaria Research Unit case study was approved by the Ethics Committee of the Faculty of Tropical Medicine at Mahidol University, the Tropical Research Ethics Committee at Oxford University and the Monash University Human Research Ethics Committee. In Cycle 2, the Future Health Systems case study was approved by the Johns Hopkins Bloomberg School of Public Health Institutional Review Board and the Makerere University School of Public Health Higher Degrees Research and Ethics Committee. In Cycle 3, the interviews and retrospective case studies of health research priority-setting processes were approved by the University of Melbourne Medicine and Dentistry Human Ethics Sub-Committee, the Institute of Public Health (Bangalore) Institutional Ethics Committee and the De La Salle University Research Ethics Review Committee.)

The research programme to develop the Research for Health Justice framework was led by Dr Bridget Pratt, starting as her PhD dissertation (2009 to 2012) and then as the focus of two subsequent fellowships (2013 to 2016 and 2017 to 2020) awarded to her by the National Health and Medical Research Council of Australia and the Australian Research Council, respectively. The development of the Research for Health Justice framework has involved many collaborators and research assistants over the years. This is reflected in the authorship (and acknowledgements) of the Research for Health Justice framework publications cited in this paper and those that are currently under review. In Cycle 1, the conceptual 
Table 1 Research for Health Justice guidance for designing and investing in global health research projects

\begin{tabular}{|c|c|}
\hline $\begin{array}{l}\text { Framework } \\
\text { domain }\end{array}$ & Guidance \\
\hline $\begin{array}{l}\text { Research } \\
\text { population }\end{array}$ & $\begin{array}{l}\text { External researchers from } \\
\text { HICs: Seek partnerships in a } \\
\text { host country(ies) that exhibits a } \\
\text { sizeable gap in health or well- } \\
\text { being from the optimal level } \\
\text { achieved worldwide. } \\
\text { All researchers: Where } \\
\text { the research findings can } \\
\text { be generalised to worst-off } \\
\text { populations within host the } \\
\text { country, select a research } \\
\text { population or host community } \\
\text { that exhibits health or well- } \\
\text { being close to the optimal level } \\
\text { achieved in the host country. } \\
\text { Where the research findings } \\
\text { cannot be generalised to worst- } \\
\text { off populations within the host } \\
\text { country, select a research } \\
\text { population or host community } \\
\text { that either: } \\
\text { exhibits a sizeable gap in } \\
\text { health or well-being from the } \\
\text { optimal level achieved in the } \\
\text { host country, or } \\
\text { sufficiently includes such } \\
\text { communities/populations } \\
\text { to be able to produce } \\
\text { knowledge of difference } \\
\text { or equivalence of health } \\
\text { or health system issues } \\
\text { across different social or } \\
\text { geographical stratifiers, or } \\
\text { intersections between severa } \\
\text { stratifiers. }\end{array}$ \\
\hline
\end{tabular}

How to uphold the guidance in research practice

To select host countries based on health status, consider:

1. The level of health achievement*: does the country's population exhibit a large gap in health status from the optimal level† achieved worldwide?

2. The level of health security: does the country have a low prospect of sustaining its achieved level of population health over time?

3. The length of time: how long has the country experienced poor health achievement and/or health security? AND

4. The level of health inequality within a country: does the country have high health inequality relative to the optimal/lowest level achieved worldwide?

The gap from the optimal global level of health achievement (best achieved worldwide) and health inequality (lowest achieved worldwide) should be substantial: Host countries should fall into bottom third of performers worldwide.

Those countries that exhibit all four characteristics are seen as being of highest priority.

To select host countries based on well-being status, consider:

1. The level of poverty: does the country exhibit a large gap in the amount of poverty its population experiences relative to the optimal level of poverty achieved worldwide? This identifies countries with the greatest poverty worldwide, using multidimensional poverty metrics, eg Multidimensional Poverty Index $\neq$, rather than unidimensional poverty metrics, eg Below the Poverty Line.

2. The length of time: how long has the country experienced high levels of poverty? AND

3. The level of within-country inequality: does the country have a sizeable gap in well-being between the poor and the rest of its population? This identifies countries with the largest gaps between the rich and poor.

The gap from the optimal global level of poverty (lowest achieved worldwide) and inequality (lowest achieved worldwide) should be substantial: Host countries should fall considerably above the optimal multidimensional poverty levels achieved worldwide (ie, 0 ); they should fall into the bottom third of performers worldwide.

Those countries that exhibit all three characteristics are seen as being of highest priority.

To select research populations or host communities based on health status, consider:

1. The level of health achievement: does the population exhibit a small or large gap in health status compared with the healthiest populations in the host country?

2. Access to healthcare and services: does the population have similar or substantially worse access to healthcare and services compared with the populations in the host country with the best access? AND/OR

3. Financial protection against catastrophic health spending: does the population have similar or substantially worse protection against catastrophic health spending compared with the populations in the host country with the best protection?

Where research findings can be generalised, the gap from the optimal level of health attainment, access to Where safety concerns or funding healthcare and services and financial protection (best achieved in the country) should be small: Research constraints prevent conducting projects in certain regions of the host country, researchers should, nonetheless, work with populations or communities that meet the above criteria in those regions of the country where they are able to perform research populations should fall into the top third of performers in the country.

Where research findings cannot be generalised, the gap from the optimal level of health attainment, access to healthcare and services and financial protection (best achieved in the country) should be large: Research populations should fall into the bottom third of performers in the country or sufficiently include such populations.

To select research populations or host communities based on well-being status, consider:

1. Domination: is the research population a dominated or non-dominated group within the country? A dominated group is a group whose members are not treated as dignified human beings worthy of equal moral concern simply because they are part of the group. They are not given equal respect. They are often stigmatised or discriminated against due to being group members. Dominated groups can be defined by different characteristics such as gender, ethnicity, race, caste, sexual orientation and/or living with disability. OR

2. Poverty: does the population exhibit a small or large gap in the amount of poverty it experiences compared with other populations in the host country? This would identify populations with the least or greatest poverty in the country, using multidimensional poverty metrics, eg Multidimensional Poverty Index, rather than unidimensional poverty metrics, eg Below the Poverty Line.

Where research findings can be generalised, the research population should be a non-dominated group, or exhibit a small gap if any from the optimal level of poverty (lowest achieved) in the country. Where the research population exhibits a small gap, it should fall into the top third of performers in the country (in terms of the proportion of its members classified as multidimensionally poor).

Where research findings cannot be generalised, the research population should be a dominated (eg, stigmatised or discriminated) group, exhibit a large gap from the optimal level of poverty (lowest achieved) in the country or sufficiently include such populations. Where the research population exhibits a large gap, it should fall into the bottom third of performers in the country (in terms of the proportion of its members classified as multidimensionally poor).

Continued 
Table 1 Continued

Framework domain Guidance
How to uphold the guidance in research practice
Research topic and question
All researchers: Select an equityoriented research question through an inclusive process, involving not only the research team but also relevant community members.§

Involving community members who are considered disadvantaged or marginalised is essential to ensure that their voices are captured and reflected in projects' research topics and questions.

\section{Process of selection}

Research questions should be selected through processes with the following features:

Leadership Where health research projects are a collaboration between external and local senior researchers from the host country, senior local researchers should lead or be among those leading the selection of the

ty research topic and questions. Where more junior local researchers partner with senior external researchers, initially, senior external researchers may be more likely to lead priority-setting. Over the course of the partnership, however, local researchers' research capacity should be enhanced, possibly through learning by doing approaches. For long-term partnerships, local researchers should lead or be among those leading the selection of research topics and questions for collaborative projects.

It is also important that, where research teams include community partners, they are among those leading health research priority-setting.

Community partners could be community organisations, disabled persons organisations, NGOs, persons with lived experience, service users, patients, members of the public, service providers and/or policymakers. Ideally, one or more community partner(s) should represent and be able to access the research population or host community, including those who are considered disadvantaged or marginalised within it. For more guidance on selecting community partners, see online supplemental file 1.

Who participates All members of the research team, including community partners, should ideally participate. However, where the research team is very large, it may be necessary to rely on representatives. Here, inclusion demands that participants in priority-setting processes not only represent all the different partner institutions/organisations but also reflect the range of positions and demographics within them, for example, men and women, senior and junior faculty members and postdoctoral researchers, etc. It is highly desirable that a greater number of representatives from LMIC institutions/organisations be included relative to HIC institutions/organisations.

Community members from the research population or host community should also participate. They could include: patients, carers, people with lived experience, members of the public, policymakers, community leaders, and/or health carehealthcare providers. Two reasons for selecting community participants are suggested:

1. they have pertinent knowledge of the health needs of those considered disadvantaged or marginalised or

2. they have the power to change policies and practices that affect the health of those considered disadvantaged or marginalised.

Here, achieving diversity and sufficient mass of community members is also important. Achieving diversity means that participants span a wide spectrum of relevant roles in the two categories (eg, patients, policymakers) and include those considered disadvantaged or marginalised within the host community or research population. Sufficient mass means the number of community partner staff and community members is greater, equal or, at a minimum, not too different from the number of academic researchers during priority-setting.

Scope of priority-setting Ideally, health research priority-setting processes have an open scope to set health research topics - no or very few topics related to health are off the table-articulate research questions, and design interventions. But funding and other constraints often make this impossible. In such cases, it is essential to be transparent with partners and communities about what health problems and interventions can and cannot be the focus of priority-setting and subsequent research projects, and why.

How they participate There are four phases of priority-setting in research projects:

1. Conceptualising and planning the priority-setting process,

2. Research topic solicitation,

3. Research topic prioritisation and

4. Formulating the research question(s) and interventions

All research team members/representatives should participate from the start of priority-setting and community members should participate from either the start of priority-setting or, at a minimum, from research topic solicitation.

Power is more evenly shared where community partners and members participate in health research prioritysetting as collaborators (decision-makers) rather than as consultants. For a given project, the research topic and questions are ideally set through a deliberative process that is structured to pay attention to power disparities between participants.

Being deliberative means participants are able to voice their ideas for research topics and questions, how they should be prioritised and the reasons behind their selections. Once suggestions have been made and justified, the entire group of participants then should have an opportunity to debate the pros and cons of various proposals. Proposals are refined and/or weeded out and participants coalesce around their preferred option(s). The final outputs (research topic and questions) are agreed on by all participants. 
Framework domain
Guidance
How to uphold the guidance in research practice

In some cases, however, it may be necessary to consult community members or to use a mix of consultative and deliberative methods. For example, consultations may be ethically necessary because community members cannot safely share the same deliberative space. Even so, mixed and pure consultative mechanisms can still share decision-making power with the community where local researchers, community partners and field investigators from the community participate in identifying research topics from the data collected at consultations with the wider community, prioritising among them and formulating research questions. For more guidance here, see online supplemental file 2.

The priority-setting process should be structured to ensure that LMIC participants, especially those considered disadvantaged or marginalised, have a greater or equal chance to speak during consultations and deliberations. This might entail setting certain ground rules that give greater time to LMIC participants to speak, privilege ways of speaking like storytelling and rhetoric and affirm everyone has an equal right to speak. It could also entail facilitation approaches that give an equal or greater chance to LMIC participants to speak and that make them feel comfortable sharing their views and relevant, personal stories about their country or community's health problems. Such measures (ground rules, facilitation) should also be in place to give other participants an opportunity to voice their ideas for priorities and their reasons for favouring/ opposing certain priorities.

Priority-setting should be undertaken in a space that is accessible to all participants and that is not imbued with norms, behaviours and languages that favour certain participants over others because they are better versed in those behaviours and languages or favoured by those norms.

The final outputs of priority-setting (research topic and questions) should reflect the inputs of both the research team and community members, with the inputs of all participants being treated equally or with the inputs of local researchers, community partners and community members being weighted more heavily and thus more strongly reflected in the research topic and questions.

Community partners and members should be compensated for their participation. For community partners, organisation staff members' time should be compensated at their pay rates within their organisation and individuals unaffiliated with an organisation should be employed by a research partner (in their country), put on a contract and paid at an appropriate rate. For community members, compensation should fully cover but not exceed their time and transport.

\section{Outputs of selection process}

For health systems research: Research questions should fall into one (or more) of the following categories:

1. To measure (aspects of) the performance of the host country health system in terms of achieving equal access to health services and equitable health system financing

2. To explore causes of poor health system performance in terms of equal access and equitable financing in the host country

3. To develop and evaluate an intervention to improve health system performance on equal access and equitable financing in the host country

4. To develop and evaluate an implementation strategy for an existing health system intervention or programme that has already been proven effective at improving equal access and equitable financing

5. To develop a scale-up strategy for the implementation of a health system intervention that has already been proven effective at improving equal access and equitable financing

Please note, category 3 can encompass both intervention efficacy and intervention effectiveness research.

Research questions should also focus where a need for health systems research exists and interventionsunder-study must be appropriate (acceptable and implementable) in the research population.

For basic science and clinical research: Research questions should focus on diseases that are a major contributor to shortfalls in the research population or host community's health status from the optimal level achieved worldwide. They are the major causes of the research population or host community's poor health status relative to the optimal level.

Research questions should also focus where a need for biomedical and clinical research exists. For example, clinical research-related innovation gaps will likely lie in the following areas:

1. Developing prevention interventions and treatments for diseases where none exist.

2. Developing treatments for diseases where emerging resistance or other factors have significantly reduced the effectiveness of existing treatments.

3. Adapting and optimising existing prevention interventions and treatments so that they are accessible and affordable in resource-poor settings (eg, vaccines that don't require refrigeration).

Finally, where such research tests an intervention, the intervention-under-study must be appropriate (acceptable and implementable) for the research population or host community.

Long-term collaborations should alter their research agendas to align with changes in the burden of disease experienced by their research populations, that is, changes in the diseases driving their gap in health status from the optimal level. The transition may be made more gradually in contexts where the disease-specific nature of research expertise and the research funding environment create barriers. 
Table 1 Continued

\begin{tabular}{ll}
\hline $\begin{array}{l}\text { Framework } \\
\text { domain }\end{array}$ & Guidance \\
\hline $\begin{array}{l}\text { Research } \\
\text { capacity } \\
\text { development }\end{array}$ & $\begin{array}{l}\text { Build the independent capacity of } \\
\text { LMIC institutions and researchers } \\
\text { to perform health research." }\end{array}$ \\
& "Here, the framework is not \\
& suggesting that capacity \\
building cannot or should not & be performed for HIC research \\
& partners. It recognises that \\
& capacity development is a two- \\
& way process than can occur from \\
& HIC to LMIC, LMIC to HIC, HIC to \\
& HIC and LMIC to LMIC partners. \\
Instead, the framework is arguing & that strengthening the capacity \\
& of LMIC partners is a priority as \\
a matter of justice, particularly \\
given that funding for capacity \\
development within individual \\
research projects is usually \\
limited. Those resources should \\
be spent on LMIC partners to \\
help reduce global disparities in \\
research capacity. Nonetheless, \\
it is also important that HIC \\
researchers learn from these \\
partnerships and, for example, \\
build their understanding of \\
diverse types of knowledge and \\
their awareness that different \\
ways of knowing count and are \\
valid.
\end{tabular}

Ancillary care All researchers: Deliver ancillary care to study participants for a limited subset of conditions that meet certain criteria.
How to uphold the guidance in research practice

Research projects should:

Be conducted through partnerships with local research groups and institutions in the host country. These should generally be of lengthy duration and span more than one project.

2. Use strategies that build independent LMIC research capacity at the individual and institutional levels. 1. Individual level strategies for junior researchers could include:

i. Completion of post-graduate degrees or post-doctoral positions

ii. Learning by doing: Places for junior researchers on grants

2. Individual level strategies for senior researchers could include:

i. Learning by doing: Have principal investigators from LMIC partners

ii. Devolving responsibility

3. Institutional level strategies could include:

i. Building financial management and technical capacity

ii. Building post-graduate education programmes for health research

iii. Building research teams

iv. Linking institutions with weak research capacity to institutions with strong capacity

3. Be tailored to address the particular needs of LMIC research institutions and their investigators.

4. Build research-to-policy or research uptake and translation capacity.

5. Use capacity development strategies that have been proven effective.

Continued 
Table 1 Continued

\begin{tabular}{|c|c|c|}
\hline $\begin{array}{l}\text { Framework } \\
\text { domain }\end{array}$ & Guidance & How to uphold the guidance in research practice \\
\hline $\begin{array}{l}\text { Knowledge } \\
\text { translation }\end{array}$ & $\begin{array}{l}\text { All researchers: Create lasting } \\
\text { change to reduce health } \\
\text { disparities. }\end{array}$ &  \\
\hline
\end{tabular}

*The health capability paradigm endorses relying on "an indicator of length of life related to the central health capability of avoiding premature mortality."[32, p. 200] It does not endorse using one indicator over all others. There is flexibility to rely on different measures. This is because many current measures have shortcomings. For example, there is significant debate as to whether the DALY and the age and disability-weights it uses are appropriate. ${ }^{52}$ Depending on the weights used, different priorities may be identified. Ruger therefore, does not endorse the DALY as the definitive measure of shortfall inequality, but the health capability paradigm does not entirely reject the DALY or other disability and morbidity-related measures of disease burden like the QALY. Such measures could be used in combination with mortality and other morbidity indicators.

†The optimal level of health in terms of morbidity and mortality indicators like life expectancy, infant mortality, maternal mortality, etc.

$\ddagger$ Multidimensional poverty measurement focusses on a set of 10 deprivations across three dimensions - health, education and standard of living. The 10 indicators are: years of schooling, school attendance, child mortality, nutrition, electricity, sanitation, water, floor, cooking fuel and assets. Each dimension is equally weighted and each indicator within a dimension is also equally weighted. A person is identified as multidimensionally poor if she/he is deprived in at least one-third of the 10 indicators. If a person is deprived in $20 \%$ to $33.3 \%$ of the 10 indicators, she/he is considered 'Vulnerable to Poverty', and if she/he is deprived in 50\% or more, she/he is identified as being in 'Severe Poverty'.

§Community membership can be based on geography; on shared interests or goals; or on shared characteristics, situations or experiences, including experiences of marginalisation. Communities can encompass (amongst others) community leaders and elders, non-aligned community members (the general public) and people who are part of the health system in the given community: namely, patients, healthcare providers, healthcare managers, insurers, policymakers and others. Community members are not part of the research team that initiates the priority-setting process.

IDevolving responsibility means a visible change in the balance of responsibilities is achieved over the course of joint projects. For example, where LMIC partners have very little capacity at the start of a collaboration, they might eventually take over the day-to-day implementation of research in their country from HIC partners. ${ }^{18}$

DALY, disability-adjusted life year; HIC, high-income countries; LMIC, low- and middle-income countries; NGOs, non-governmental organisations; QALY, quality-adjusted life year.

and empirical work was conducted in collaboration with Associate Professors Bebe Loff (Monash University) and Deborah Zion (then at Monash University), who are both ethics researchers with expertise in philosophical ethics and qualitative methods. The Cycle 1 case study was conducted in collaboration with Associate Professors Zion and Loff and clinical researchers at the Shoklo Malaria Research Unit: Dr Phaik Yeong Cheah, Dr Khin Maung Lwin and Dr Francois Nosten. These collaborations are reflected in the authorship of publications emerging from this work. ${ }^{4} 14$ 19-21 In Cycle 2, the conceptual and empirical work was conducted in collaboration with Professor Adnan Hyder (then at Johns Hopkins Bloomberg School of Public Health and the Berman Institute of Bioethics), who has expertise in health systems research and empirical ethics methods. This collaboration is reflected in the authorship of publications emerging from that work. ${ }^{22-29}$ In the Future Health Systems case study, it was decided that researchers from Future Health Systems and Makerere University would not be involved as collaborators to minimise the risk of conflicts of interest affecting data collection and analysis. The case study was, however, designed and conducted with their approval and support. (For case studies, it is generally left up to researchers or others from the project-under-study to decide whether they want to be collaborators or have another role.) Additionally, Dr Katharine Allen (Johns Hopkins) served as a research assistant on the Future Health Systems case study, leading quantitative data analysis and assisting with qualitative data analysis. She is a co-author on papers reporting the quantative data. ${ }^{30}$ In Cycle 3 , the two retrospective case studies were conducted in collaboration with 
Table 2 Research for Health Justice guidance for designing global health research grants programmes

\begin{tabular}{|c|c|c|c|}
\hline Framework domain & Guidance & $\begin{array}{l}\text { How to uphold the guidance: } \\
\text { Corresponding feature of grant } \\
\text { programme design }\end{array}$ & $\begin{array}{l}\text { Examples from existing grants } \\
\text { programmes }\end{array}$ \\
\hline Research population & $\begin{array}{l}\text { Target health research to } \\
\text { badly-off countries and } \\
\text { populations within them }\end{array}$ & $\begin{array}{l}\text { 1a. Restrict host countries to those badly- } \\
\text { off in health terms } \\
\text { OR } \\
\text { 1b. Restrict host countries to those badly- } \\
\text { off in terms of multidimensional poverty } \\
\text { 2. Require or prioritise research performed } \\
\text { with or focussed on those considered } \\
\text { disadvantaged, marginalised and/or } \\
\text { vulnerable within countries, for example, } \\
\text { populations or communities exhibiting } \\
\text { worse health status or multidimensional } \\
\text { poverty status relative to the national } \\
\text { average }\end{array}$ & $\begin{array}{l}\text { 1a. Focal countries of grant } \\
\text { programme are countries where } \\
\text { the under-five mortality rate is } \\
\text { above } 80 \text { per } 1000 \text { live births and/ } \\
\text { or where the maternal mortality } \\
\text { rate is above } 300 \text { per } 100000 \text {. } \\
1 \text { b. Focal countries of grant } \\
\text { programme are largely low- } \\
\text { income, including fragile and post- } \\
\text { conflict states. } \\
2 . \text { Grantmaking principle: Priority } \\
\text { will be given to research that } \\
\text { benefits the most vulnerable } \\
\text { populations. }\end{array}$ \\
\hline & & & $\begin{array}{l}\text { 3. Grantmaking principle: } \\
\text { Consulting and engaging others, } \\
\text { particularly marginalised groups. }\end{array}$ \\
\hline $\begin{array}{l}\text { Research topics and } \\
\text { questions (outputs) }\end{array}$ & $\begin{array}{l}\text { Focus research on improving } \\
\text { equitable healthcare and } \\
\text { systems }\end{array}$ & $\begin{array}{l}\text { Require research to generate new } \\
\text { knowledge to improve access to high- } \\
\text { quality health services and/or financial } \\
\text { protection for those considered } \\
\text { disadvantaged or marginalised within } \\
\text { countries }\end{array}$ & $\begin{array}{l}\text { Grantmaking principle that calls } \\
\text { for research to address the root } \\
\text { causes of unequal access to } \\
\text { primary health services. }\end{array}$ \\
\hline
\end{tabular}




\begin{tabular}{|c|c|c|c|}
\hline Framework domain & Guidance & $\begin{array}{l}\text { How to uphold the guidance: } \\
\text { Corresponding feature of grant } \\
\text { programme design }\end{array}$ & $\begin{array}{l}\text { Examples from existing grants } \\
\text { programmes }\end{array}$ \\
\hline $\begin{array}{l}\text { Research capacity } \\
\text { development }\end{array}$ & $\begin{array}{l}\text { Develop independent } \\
\text { LMIC research capacity at } \\
\text { individual, teams, institutional } \\
\text { and systems levels }\end{array}$ & $\begin{array}{l}\text { Require and support applicants to } \\
\text { help create a 'critical mass' of LMIC } \\
\text { researchers, teams and research } \\
\text { institutions, with networks connecting } \\
\text { them, that can obtain funding and perform } \\
\text { research on their own }\end{array}$ & $\begin{array}{l}\text { Require applicants to have } \\
\text { capacity building strategies } \\
\text { and have selection criteria } \\
\text { assessing their quality, including } \\
\text { having realistic and achievable } \\
\text { plans for building independent } \\
\text { LMIC capacity at individual and } \\
\text { institutional levels, for example, } \\
\text { Postgraduate education } \\
\text { Learning by doing } \\
\text { Devolving responsibility } \\
\text { Building grants management } \\
\text { and technical capacity } \\
\text { Building postgraduate } \\
\text { education programmes in } \\
\text { health research }\end{array}$ \\
\hline
\end{tabular}

\begin{tabular}{|c|c|c|c|}
\hline Ancillary care & $\begin{array}{l}\text { Deliver ancillary care to study } \\
\text { participants }\end{array}$ & $\begin{array}{l}\text { Require and support the identification } \\
\text { of ethically essential ancillary care } \\
\text { and support its provision by study } \\
\text { investigators. } \\
\text { (See table } 1 \text { for more information on what } \\
\text { comprises ethically essential ancillary } \\
\text { care.) }\end{array}$ & $\begin{array}{l}\text { Budget permits support for } \\
\text { systems that enable researchers } \\
\text { to identify ancillary care needs } \\
\text { (eg, epidemiological surveys, } \\
\text { clinic data collection systems or } \\
\text { gathering information from local } \\
\text { clinical staff) and for providing } \\
\text { ethically essential ancillary care. }\end{array}$ \\
\hline Knowledge translation & $\begin{array}{l}\text { Have a lasting impact on } \\
\text { health disparities }\end{array}$ & $\begin{array}{l}\text { 1. Require applicants to have research } \\
\text { translation objectives and strategies } \\
\text { that promote changes in policy and } \\
\text { practice to benefit those considered } \\
\text { disadvantaged or marginalised within } \\
\text { host countries. Offer budgetary } \\
\text { support to implement those strategies. } \\
\text { 2. Require applicants to promote } \\
\text { intervention sustainability as part of } \\
\text { research translation (where applicable). } \\
\text { Offer budgetary support to implement } \\
\text { sustainability strategies. }\end{array}$ & $\begin{array}{l}\text { 1. Grantmaking principle: } \\
\text { Informing and influencing } \\
\text { policy, practice and agendas } \\
\text { to strengthen equitable health } \\
\text { systems; Require } 10 \% \text { of } \\
\text { project budget be designated } \\
\text { for knowledge translation. } \\
\text { 2. Grantmaking principle: Making } \\
\text { lasting change. }\end{array}$ \\
\hline
\end{tabular}

HIC, high-income countries; LMIC, low- and middle-income countries.

health systems researchers from the Institute of Public Health (Bangalore, India) - Dr Prashanth N Srinivas and Dr Tanya Seshadri-and public health researchers from De La Salle University (Philippines) and the University of Melbourne-Associate Professors Jesusa M Marco and Cathy Vaughan. Five research assistants from the University of Melbourne, Institute of Public Health and the University of the Philippines helped to organise and conduct data collection and to assist with data analysis. Papers from these case studies are under review or in the process of being written, but authorship includes named collaborators in each case. This paper brings the work described in those publications together and its integration was conducted by Dr Pratt.

\section{Cycle 1}

Conceptual work was undertaken to identify a theory or theories of global justice from political philosophy capable of serving as the basis of a framework linking global health research to the reduction of global health inequities. To serve such a role, a theory needed to:
(1) establish health-related obligations of justice that apply to actors that perform global health research, (2) provide a second-tier mechanism that allocates specific duties (toward the fulfilment of the health-related obligations) to specific global health research actors and (3) offer additional direction that can substantively guide the model of global health research. ${ }^{4}$ The reason for focussing on theories of global justice was that they ground ethical obligations between actors from different countries. Theories of global justice could thus conceivably be applied to identify the ethical responsibilities of external researchers to researchers and communities in host countries. This is important in global health research since it frequently involves researchers working in countries that they do not live in and/or of which they are not citizens. (It should be noted, however, that debate continues within philosophy over whether obligations of justice are owed to individuals outside one's own nation-state. Cosmopolitan theorists argue that whatever the correct principles of distributive justice are, they ought to apply 
identically to everyone worldwide. Anti-cosmopolitans or social liberal theorists contend that certain principles of 'humanity' may apply identically to everyone worldwide, but principles of 'justice' only apply among citizens of the same state. Others take a middle position, saying that, while some principles of justice do apply globally, these principles are different and/or much less demanding than the robust (ie, 'egalitarian') ones that apply domestically. ${ }^{31}$ Relevant to this paper, Henry Shue and Thomas Pogge both take a cosmopolitan position and Jennifer Ruger and Norman Daniels take a middle-ground position.)

The health capability paradigm was identified as meeting all four criteria, while the other theories did not. ${ }^{4}$ Most problematically, the three other theories did not have a second-tier mechanism that allocates specific duties. They went no further than affirming that (affluent) parties worldwide owe health-related obligations to individuals in LMICs. Without second-tier principles for distributing responsibilities, these theories of justice offered little argument for why specific actors like researchers ought to act in specific ways to advance global health equity. ${ }^{4}$ In contrast, the health capability paradigm's functional requirements principle assigns actors obligations based on their functions in the global health architecture. Clinical researchers' functions, for example, identify them as being specifically charged with working with LMICs to (1) create new health interventions, (2) adapt existing health interventions for use, (3) strengthen their clinical research capacity, (4) provide ancillary care and (5) promote research uptake and translation. ${ }^{4}$

The health capability paradigm is a theory of global justice that extends the capability approach of Amartya Sen and Martha Nussbaum and specifically addresses health. It establishes a universal obligation to efficiently reduce shortfall inequalities in individuals' health capabilities. The theory has several main principles (ie, justice should be assessed in terms of shortfall inequalities in health capabilities, functional requirements, priority to the worst-off, efficiency) and offers guidance on how global health justice should be promoted (direct assistance, capacity-building,shared health governance). Health capabilities refer to individual ability and freedom to achieve certain health functionings (ie, avoiding preventable morbidity and mortality) and health agency (ie, being able to make effective health choices). As health capabilities are not directly observable, reducing shortfall inequalities in individuals' health capabilities refers to diminishing the gap in their health status from the optimal level (the highest level of health achieved worldwide in terms of morbidity and mortality indicators). Health functionings or achievements map directly on to health capabilities, so individuals' health status can be used as a rough proxy indicator of their health capability. ${ }^{32}$ Priority is given to addressing shortfalls in the health capabilities of those farthest from the optimal level of health. ${ }^{33}$ The functional requirements principle assigns parties obligations because the functions they typically assume make them particularly capable of fulfilling the obligations. ${ }^{33}$ The health capability paradigm applies efficiency considerations to equity goals. States and global actors should fulfil their obligation to reduce shortfall inequalities in individuals' health capabilities using as few resources as possible. ${ }^{32}$

According to the health capability paradigm, achieving justice in health means first meeting the health entitlements of people who are worst-off in health terms in countries worldwide. ${ }^{33}$ Where nation-states are unable to ensure their own population's health capabilities, justice requires that global actors assist states to meet their obligation and build states' capacity to do so on their own. ${ }^{33}$ Shared health governance describes the type of governance needed to achieve global health justice and identifies five components as essential: advancing the goals of health justice, shared sovereignty, shared resources, shared responsibility and mutual collective accountability. ${ }^{34} 35$

It is important to note the health capability paradigm's principles and concepts are consistent with other theories of justice, primarily other capability theories, cosmopolitan theories and prioritarian theories. As reported in Pratt $e t a l,{ }^{22}$ capability theorists, Martha Nussbaum and Sridhar Venkatapuram, have purported that all individuals are entitled to a set of basic capabilities, including health. The health capability paradigm's focus on the worst off is consistent with other prioritarian theories of justice such as that of Madison Powers and Ruth Faden. ${ }^{22}$ Where states are unable to ensure health justice for their populations, numerous cosmopolitan theories support an obligation for external actors to improve the health of individuals in these states. The health capability paradigm calls for global actors to not only assist states to meet their obligation but also build states' capacity to do so on their own. Other theorists' work supports this a dual role for global actors, including Henry Shue and Iris Marion Young. ${ }^{22}$ Additionally, recent work has compared the health capability paradigm's principles of shared health governance to those of Ubuntu, an African moral theory used predominantly in Southern African countries. That work shows that the principles of shared health governance are largely shared by Ubuntu. ${ }^{36}$

Once the health capability paradigm was selected, Research for Health Justice requirements for international basic science and clinical research were derived from it. This starting point reflected the fact that basic science and clinical research are/were the most common types of global health research being performed. Medical and clinical research had also been the primary focus of concerns of exploitation and injustice in the ethics literature ${ }^{937}$ and thus seemed an important target of equity-oriented ethical guidance. Elements of the health capability paradigm were applied in light of basic science and clinical research's distinctive features. These elements include the paradigm's requirements for health systems, the 
theory's main principles and its guidance on how global health justice is promoted (direct assistance, capacitybuilding, shared health governance). (According to the health capability paradigm, a just health system has two main features: (1) equal access to high quality goods and services (ie, public health goods and services, healthcare goods and services and health-related social services) and (2) equitable health financing. Equal access consists of four core elements: horizontal equity, quality, agency and norms. ${ }^{32}$ ) The conceptual work applying elements of the health capability paradigm generated initial guidance on how to design basic science and clinical research to produce new knowledge that contributes to increased freedom for those considered disadvantaged and marginalised to achieve good health. ${ }^{19}$

Empirical work was next performed to test the framework's initial guidance against the practices and experiences of those involved in equity-oriented international clinical research. The Shoklo Malaria Research Unit's vivax malaria treatment trial was selected because, for the past 30 years, Shoklo has been consciously designing its clinical trials to meet the health needs of its host community. It conducts its research with the population of Karen and Myanmar refugees, migrants, and displaced persons living on the Thai-Myanmar border. Shoklo's vivax malaria treatment trial aimed to describe the epidemiology and compare the efficacy of three treatments for vivax malaria-chloroquine/primaquine, chloroquine and artesunate.

For the case study, data on the vivax malaria treatment trial were collected using a triangulation approach that relied on in-depth interviews, direct observation and document analysis. Semi-structured in-depth interviews were conducted with four types of trial stakeholdersresearchers, Tak Province Border Community Ethics Advisory Board members, trial participants and Wellcome Trust science portfolio advisors. Interview data were supplemented by direct observation at four of the five trial sites over a 5-week period and by an examination of trial-related documents. Data were thematically analysed. ${ }^{38}{ }^{39}$ In light of case study findings, revisions to the initial Research for Health Justice framework were proposed. ${ }^{1421}$ Major findings of Cycle 1 are reflected in the framework's guidance on the outputs of research topic and question selection for biomedical and clinical research, the provision of ancillary care and much of the guidance on research capacity development.

\section{Cycle 2}

Conceptual work was performed to expand the Research for Health Justice framework's guidance to health systems research. Health systems research has repeatedly been identified as an indispensable means to the goal of achieving health equity. ${ }^{6} 7$ Externally-funded health systems research is also increasingly being performed in $\mathrm{LMICs}^{40}$ and has distinctive features relative to basic science and clinical research that restrict the applicability of existing ethical guidance. ${ }^{41}$ Alternative or nuanced guidance was needed to link health systems research to the reduction of health disparities between and within countries. ${ }^{23}$

The aforementioned elements of the health capability paradigm were, therefore, applied in light of health systems research's distinctive features. ${ }^{23}$ Additionally, in some instances, the health capability paradigm was supplemented by other accounts that considered certain matters with greater specificity. For example, the paradigm calls for inclusive, deliberative decision-making but does not describe what inclusion or deliberation entails in sufficient detail. As such, Iris Marion Young and other philosophers' work on inclusion in decision-making in contexts of power disparities was applied to generate more specific guidance on shared decision-making in setting research agendas. Those philosophers' work and the guidance derived from it is comprehensively described in Pratt et al (2016, p. 37-39). ${ }^{22}$ That guidance is included in the 'research for health justice' framework and describes who should be included in priority-setting from the research team, when research team members should participate, what being deliberative means and how the deliberative process should be undertaken (ie, that it is structured to pay attention to power disparities between participants and to ensure that LMIC participants have a greater or equal chance to speak) (see table 1, Column 3 'How to uphold the guidance in research practice' for research topics and questions).

Empirical work was conducted to test the framework's guidance for health systems research against the experiences and practices of those involved in equity-oriented health systems research in LMICs. Case study research was carried out on the Future Health Systems consortium and one of its projects: the Maternal and Neonatal Implementation for Equitable Health Systems (Manifest) project in rural Uganda. Future Health Systems was selected because it was performing health systems research to improve the equity of service delivery in LMICs, specifically Bangladesh, China, India and Uganda. The Manifest project was selected as a nested case study. It was undertaken by researchers from Makerere University in partnership with district health teams in three rural Ugandan districts. The project aimed to develop sustainable mechanisms for improving access to, and the quality of, maternal and child health services in rural Uganda. Within Uganda, a sizeable disparity in access exists between urban and rural areas. Again, case study data were collected using a triangulation approach. In-depth interviews were performed with senior Future Health Systems researchers from HICs and LMICs, junior Future Health Systems researchers from LMICs, Makerere researchers working on the Manifest project, health provider partners (district health teams) on the Manifest project, local implementing partners (village health workers, community development officers) on the Manifest project and funders (the UK Department for International Development and Comic Relief). For the nested Manifest case, interview data were supplemented by direct observation in two of the three 
host districts over a 2-week period and by an examination of study-related documents. Data were thematically analysed. $^{38} 39$

To further test the framework's guidance for funders, a qualitative study was done to examine how the largest health systems research funders design their grants programmes. Semi-structured, in-depth interviews were performed with 16 grants officers working for 11 funders and organisations that support health systems research in LMICs. Interviews focussed on each funder's largest health systems research grants programme in LMICs and data were thematically analysed. ${ }^{38} 39$

In light of the three studies' findings, ways to improve the Research for Health Justice framework's guidance for health systems research were proposed and new conceptual work was undertaken. That work again used additional theories to supplement the health capability paradigm. ${ }^{25-27} 29$ Based on the finding that, in practice, research populations were selected due to being worst-off in terms of health or overall well-being, ${ }^{25} 28$ theories of social justice that address disadvantage and well-being (eg, the work of Madison Powers, Ruth Faden, Jonathan Wolff and Avner de-Shalit) were applied to generate more comprehensive guidance on selecting research populations based on overall levels of well-being (rather than health alone). That guidance is described comprehensively in Pratt and Hyder et al $(2016)^{24}$ and is included in the Research for Health Justice framework (see table 1, Columns 2 'Guidance' and 3 'How to uphold the guidance in research practice' for Selecting Research Populations).

Other major findings of Cycle 2 were more comprehensive guidance on how to select research populations that are worst-off in terms of health, balancing selecting worst-off research populations with safety concerns and the outputs of research topic and question selection for health systems research. Much of the guidance presented in table 1 on creating lasting change (aside from that related to product development partnerships) and in table 2 for funders reflect Cycle 2 findings.

\section{Cycle 3}

The Manifest case raised questions about the nature of shared decision-making between academic researchers and community partners that the Research for Health Justice framework did not answer. Cycle 3 was, therefore, performed to strengthen framework's guidance around inclusive research priority-setting with communities, particularly those considered disadvantaged or marginalised. Sharing decision-making power with such communities in agenda-setting is essential to ensure their voices and knowledge are reflected in the research topics and objectives of global health research projects. This, in turn, can help address epistemic injustice and generate research topics and objectives that are more explicitly focussed on improving access and affordability of healthcare and services for them. ${ }^{42}{ }^{43}$ (Epistemic injustice occurs when those considered disadvantaged or marginalised are susceptible to unjust credibility deficits, which prevents their views from being solicited. They are not asked to provide their knowledge, opinions, thoughts or judgements. ${ }^{44}$ Epistemic justice means giving proper respect to individuals as knowers and sources of information. ${ }^{44}$ )

To identify how global health research priority-setting should be designed to share power with communities, six key bodies of literature that discuss participation in contexts of power disparities were analysed for components of engagement and their associated sites of power. Sites of power are features of priority-setting (eg, ground rules, facilitation) that affect who shapes priority-setting processes, who participates and who is heard in them. The bodies of literature included development studies, political philosophy, ethics, health priority-setting, public deliberation and community-based participatory research. Conceptual work was then undertaken to identify ethical considerations related to power-sharing at each site in global health research priority-setting. ${ }^{45}$

Empirical work was next performed to explore key informants' perspectives on what is necessary to share power with communities, especially those considered disadvantaged and marginalised, in global health research priority-setting. Here, components of engagement, sites of power and ethical considerations identified by the conceptual work were tested against the experiences and perspectives of researchers, ethicists, community engagement practitioners, community-based organisation staff and people with lived experience and members of the public who have been engaged in health research. Fifty-one in-depth interviews and one focus group were performed. Those recruited for in-depth interview came primarily from Australia, the UK and Europe, and Africa as well as, to a lesser extent, from North America, Latin America and Southeast Asia. The 13 researchers who were interviewed worked in multiple fields of health research, including genomics, clinical, public health and health systems research.

Two retrospective case studies of health research priority-setting processes, where communities were involved as partners, were conducted as well. The cases looked at priority-setting in a health systems research project in India and a public health research project in the Philippines. For each, in-depth interviews were performed on-site in Bangalore and the BR Hills (India) and Manila (Philippines), respectively, with academic researchers, community partners, field investigators from the community and community members who participated in priority-setting. Interview data was again thematically analysed. ${ }^{38} 39$

The conceptual and empirical work generated guidance on how priority-setting should be designed so that that community partners and their communities' knowledge and voices are visible in research projects' topics and questions. ${ }^{45}{ }^{46}$ In this paper, that guidance (some published and some currently under review) has been incorporated into the 'research for health justice' 
framework. All framework guidance on how community members should be involved in the process for selecting research topics and questions is drawn from Cycle 3 findings. Guidance on scope, space, facilitation and ground rules for the process are also drawn from Cycle 3 findings (see table 1, Column 3 'How to uphold the guidance in research practice' for Selecting Research Topics and Questions).

\section{THE RESEARCH FOR HEALTH JUSTICE FRAMEWORK}

The Research for Health Justice framework aims to help global health researchers and funders systematically link their practice to advancing global health equity. The framework assumes that the value of justice is central to and should guide global health research. Justice is understood in terms of equity. It should be noted that several other concepts of justice exist and have been the focus of substantial discussion in the philosophy and ethics literatures. For example, utilitarian theories of justice emphasise maximising the greatest benefits for the greatest numbers. However, as stated in the Introduction, linking global health research to justice as equity, in particular, is grounded in both theory and practice. Nonetheless, other concepts of justice and values beyond justice are also relevant to global health research (eg, non-maleficence, utility, solidarity). The framework thus considers the intersection of its guidance with upholding other values, particularly where doing so is in tension or conflict with upholding justice as equity. For example, it recommends that, where safety concerns exist in certain regions of a host country, researchers should work with worst-off populations or communities in regions of the country where it is safe to conduct research. This guidance attempts to balance tensions between justice and non-maleficence.

The Research for Health Justice framework offers guidance on what research populations and questions ought to be selected, what research capacity strengthening ought to be performed, what ancillary care ought to be provided and what post-study benefits ought to be provided and to whom in order to link global health research to global health equity. A comprehensive and up-to-date version of its guidance for researchers and funders is described in tables 1 and 2, pulling together a body of work spanning the last decade. (In health research, ancillary care is additional healthcare beyond what is essential to the conduct of the research. It is defined as healthcare that research participants need but that is not required by sound science to successfully answer the researchers' scientific question or to avoid or mitigate harm resulting from participation in the research. ${ }^{47}$ )

Global health researchers have an obligation of justice to conduct the form of global health research articulated by Research for Health Justice. This has implications for how they design their research projects (table 1). Research funders have an obligation of justice to incentivise and invest in that form of global health research.
This has implications for how they design their grants programmes, allocate their resources and manage funded projects. Table 2 provides guidance on how research funders should design their grants programmes in terms of their requirements, grantmaking principles and selection criteria. Table 1 offers them guidance on what features they should look for when selecting projects in which to invest their resources.

The Research for Health Justice framework affirms that many types of global health research are required to promote global health equity, for example, genomics, basic science, clinical, health systems and public health research, including research on the social determinants of health. So far, framework guidance has been developed specifically for basic science, clinical and health systems research. Given this, and bearing the location of the case studies informing the framework in mind, its guidance is perhaps most directly applicable to basic science, clinical and health systems research in LMICs.

Nonetheless, the framework's guidance is still relevant and can be applied, to some extent, to other types of global health research and to global health research with marginalised groups in HICs. For example, the framework's general guidance on selecting research populations would apply to public health research, that is, where the research findings cannot be generalised to worst-off populations within a host country, studies should focus on research populations that exhibit a sizeable gap in their health or well-being status relative to the optimal level achieved in the host country. Inclusion of such populations' samples in genomics research would also be essential where findings would not otherwise be generalisable to them. The framework's specific guidance for basic science and clinical research is perhaps more directly relevant to fields like genomics research and its specific guidance for health systems research to fields like public health research, including research on the social determinants of health.

At a minimum, even where the framework's guidance is not perfectly matched to a given field of health research, it will be useful for global health researchers to think about how its guidance could be interpreted within their research. Such reflective practice can help them more systematically link their research projects to advancing global health equity.

\section{LIMITATIONS AND NEXT STEPS}

Significant work has been undertaken to develop the Research for Health Justice framework, and it offers global health researchers and funders robust guidance on how to link their practice to global health equity. Nonetheless, the framework is open to revisions and negotiations in light of current and future research practice, new conceptual and empirical work, and the views of additional researchers, policymakers, community members who have been engaged in health research and others. This is not uncommon for ethics guidance. 
Leading international research ethics guidelines (eg, CIOMS, Declaration of Helsinki) are regularly revised and updated.

There are also conceptual and empirical limitations to the work done to develop the Research for Health Justice framework that should be recognised and born in mind while using it. While the framework has been developed by applying several leading theories of justice, the theories come largely from scholars in the USA and Europe, though the health capability paradigm's principles of shared health governance have been shown to be consistent with the African moral theory of Ubuntu. ${ }^{36}$ Future work could usefully apply principles and concepts from non-Western theories of health and global justice to develop guidance that can inform and be incorporated into the Research for Health Justice framework. It is, however, important to note that, while the conceptual work to develop the framework has relied primarily on Western theories of justice, the case studies were performed on research projects in LMICs and with a consortium with four LMIC partners (of six partners total). The perspectives of LMIC researchers, health provider research partners, community research partners, study participants, ethicists and engagement practitioners have informed the framework's guidance through case studies and interviews.

In addition, the framework's guidance has not been specified for genomics research and public health research, which are essential for promoting global health equity. ${ }^{48}$ In relation to the latter, principles and concepts from theories of health and social justice that focus on the structural determinants of health inequities can inform the development of guidance. ${ }^{49-51}$ Case studies of public health research, including projects focussed on the social determinants of health, are necessary too. Thus far, the framework has mainly been tested against intervention studies in clinical and health systems research in LMICs. It has not been tested against descriptive, explanatory or scale up studies, or against studies with vulnerable populations in HICs or in fragile states.

Future and ongoing work is, therefore, expanding the framework's guidance to additional domains like genomics research. ${ }^{52}$ It is testing the framework's guidance against cases of research practice that ask different types of research questions and that are conducted in different settings to previous cases. For example, case study research is underway with the 'Scale-Up Diabetes and Hypertension' consortium. Unlike previous cases, this consortium's research relates to scaling up effective health system interventions for type 2 diabetes and hypertension. It operates in a high-income country (Belgium) and two middle-income countries (Slovenia and Cambodia).

Finally, more work is needed to further explore where the framework's guidance is in tension with other values relevant to global health research and to develop guidance on how to balance and/or navigate those tensions.

\section{CONCLUSIONS}

The Research for Health Justice framework offers robust ethical guidance to global health researchers and funders on how to systematically design research projects and grants programmes to promote health equity. Its development has been informed by leading theories of justice and the practices and experiences of funders and researchers working across Asia and Africa. Its use can help deliver global health research with study topics and questions that more accurately reflect the healthcare and system needs of those considered disadvantaged and marginalised, that fosters such populations' participation in decision-making about projects' design and conduct, and that generates new knowledge that is used to help improve their health.

Acknowledgements The author would like to thank Bebe Loff (Monash University), Adnan Hyder (George Washington University) and Deborah Zion (Victoria University), with whom the conceptual and empirical work in Cycles 1 and 2 was undertaken, for their vital role in helping develop the Research for Health Justice framework. The author would also like to thank all the collaborators (Phaik Yeong Cheah, Khin Maung Lwin, Francois Nosten, Sara Bennett, David Peters, Elizabeth Ekirapa-Kiracho, Prashanth N Srinivas, Tanya Seshadri, Cathy Vaughan and Jesusa Marco), research assistants (Natalia Evertsz, Nityasri S N, Katharine A. Allen, Jessica Snir, Michelle Walters and Mona Pindog) and participants in the interviews and case studies performed as part of developing the ethical framework. Without the rich data from global health research and funding practice, the ethical framework would be a much weaker and less applicable guidance document. The author would like to thank Jantina de Vries (University of Cape Town), Joyce Brown (UMC Utrecht), Kerstin Klipstein-Grobusch (UMC Utrecht) and Rieke van der Graf (UMC Utrecht). Our discussions and work together informed the thinking that is reflected in the Research for Health Justice framework presented in this paper.

Contributors BP conceived of the work and made substantial contributions to the conceptual analysis described in this paper. BP drafted the paper and gave final approval of the version to be published.

Funding BP is currently supported by a University of Melbourne R Douglas Wright Research Fellowship and a Faculty of Medicine and Health Sciences Bridging Fellowship. During the course of the research described in this paper, BP was supported by an Australian National Health and Medical Research Council (NHMRC) Early Career Sidney Sax Public Health Overseas Fellowship (Award No. 1052346) and an Australian Research Council (ARC) Discovery Early Career Researcher Award (Award No. DE170100414). BP was also supported by Future Health Systems, which was funded by the UK Department for International Development, and by an Australian Postgraduate Award scholarship (2009-2012) from the Australian Federal Government and Monash University. The contents of this article are solely the responsibility of the author and do not reflect the views of the NHMRC or the ARC. The NHMRC, the ARC and Future Health Systems did not play any role in the study design, data collection and analysis, decision to publish or preparation of the manuscript.

Competing interests None declared.

Patient consent for publication Not required.

Provenance and peer review Not commissioned; externally peer reviewed.

Data availability statement Data are available upon request.

Open access This is an open access article distributed in accordance with the Creative Commons Attribution Non Commercial (CC BY-NC 4.0) license, which permits others to distribute, remix, adapt, build upon this work non-commercially, and license their derivative works on different terms, provided the original work is properly cited, appropriate credit is given, any changes made indicated, and the use is non-commercial. See: http://creativecommons.org/licenses/by-nc/4.0/.

\section{ORCID iD}

Bridget Pratt http://orcid.org/0000-0002-4934-3560

\section{REFERENCES}

1 Benatar SR, Singer PA. Responsibilities in international research: a new look revisited. J Med Ethics 2010;36:194-7. 
2 London AJ. Justice and the human development approach to international research. Hastings Cent Rep 2005;35:24-37.

3 Pratt B, de Vries J. Community engagement in global health research that advances health equity. Bioethics 2018;32:454-63. doi:10.1111/ bioe. 12465

4 Pratt B, Zion D, Loff B. Evaluating the capacity of theories of justice to serve as a justice framework for international clinical research. Am $J$ Bioeth 2012;12:30-41.

5 Global Ministerial Forum on Research for Health. Bamako call to action on research for health. Bamako, Mali, 2008.

6 Ministerial Summit on Health Research. The Mexico statement on health research. Mexico City, 2004.

7 World Health Organization Task Force on Health Systems Research. The Millennium Development Goals Will Not Be Attained Without New Research Addressing Health System Constraints to Delivering Effective Interventions. Geneva: WHO, 2005.

8 Commission on Health Research for Development. Health research: Essential link to equity in development. Commission on Health Research for Development: Oxford, 1990.

9 Parker M, Bull S. Ethics in collaborative global health research networks. Clin Ethics 2009;4:165-8.

10 Daniels N. Equity and population health: toward a broader bioethics agenda. Hastings Cent Rep 2006;36:22-35.

11 Luna F. Poverty and inequality: challenges for the iab: iab presidential address. Bioethics 2005;19:451-9.

12 Benatar SR, Singer PA. A new look at international research ethics. BMJ 2000;321:824-6.

13 ljsselmuiden CB, Kass NE, Sewankambo KN, et al. Evolving values in ethics and global health research. Glob Public Health 2010;5:154-63.

14 Pratt B, Zion D, Lwin KM, et al. Linking international clinical research with stateless populations to justice in global health. BMC Med Ethics 2014;15:49.

15 Beauchamp TL, Childress JF. Principles of Biomedical Ethics. 7th edn. Oxford: Oxford University Press, 2013.

16 Davies R, Ives J, Dunn M. A systematic review of empirical bioethics methodologies. BMC Med Ethics 2015;16:15

17 De Vries M, Van Leeuwen E. Reflective equilibrium and empirical data: third person moral experiences in empirical medical ethics. Bioethics 2010;24:490-8.

18 Ives J, Draper H. Appropriate methodologies for empirical bioethics: It's all relative. Bioethics 2009;23:249-58.

19 Pratt B, Loff B. A framework to link international clinical research to the promotion of justice in global health. Bioethics 2014;28:387-96.

20 Pratt B, Zion D, Lwin KM, et al. Closing the translation gap for justice requirements in international research. J Med Ethics 2012;38:552-8.

21 Pratt $\mathrm{B}$, Zion D, Lwin KM, et al. Ancillary care: from theory to practice in international clinical research. Public Health Ethics 2013;6:154-69.

22 Pratt B, Hyder AA. Governance of transnational global health research consortia and health equity. Am J Bioeth 2016;16:29-45.

23 Pratt B, Hyder AA. Global justice and health systems research in low- and middle-income countries. J Law Med Ethics 2015;43:143-61.

24 Pratt B, Hyder AA. How can health systems research reach the worst-off? A conceptual exploration. BMC Health Serv Res 2016;16:619.

25 Pratt B, Hyder AA. Linking the governance of research consortia to global health justice: a case study of future health systems. J Law Med Ethics 2017;45:664-81.

26 Pratt B, Hyder AA. Linking participatory action research on health systems to justice in global health: a case study of the maternal and neonatal implementation for equitable health systems project in rura Uganda. J Empir Res Hum Res Ethics 2018;13:74-87.

27 Pratt B, Hyder AA. Governance of global health research consortia: sharing sovereignty and resources within future health systems. Soc Sci Med 2017;174:113-21.
28 Pratt B, Hyder AA. Designing research funding schemes to promote global health equity: an exploration of current practice in health systems research. Dev World Bioeth 2018;18:76-90.

29 Pratt B, Hyder AA. Ethical responsibilities of health research funders to advance global health justice. Glob Public Health 2019;14:80-90.

30 Pratt B, Allen KA, Hyder AA. Promoting equity through health systems research in low- and middle-income countries: practices of researchers. AJOB Empirical Bioethics 2016;7:199-208.

31 Ypi L, Goodin RE, Barry C, et al. Global justice, and the colonies. Philos Public Aff 2009;37:103-35.

32 Ruger JP. Health and social justice. Oxford: Oxford University Press, 2010.

33 Ruger JP. Global health justice. Public Health Ethics 2009;2:261-75.

34 Ruger JP. Shared health governance. Am J of Bioeth 2011;11:32-45.

35 Ruger JP. Global health justice and governance. Am J Bioeth 2012;12:35-54.

36 Munung NS. Developing a Principles-Based framework to link the governance of genomics research and biobanking in Africa to global health justice. PhD dissertation: University of Cape Town, 2019.

37 Hawkins J, Emanuel EJ. Exploitation in developing countries: the ethics of clinical research. Princeton, NJ: Princeton University Press, 2008.

38 Braun V, Clarke V. Using thematic analysis in psychology. Qual Res Psychol 2006;3:77-101.

39 Hruschka DJ, Schwartz D, St.John DC, et al. Reliability in coding open-ended data: lessons learned from HIV behavioral research. Field methods 2004;16:307-31.

40 Bennett S, Adam T, Zarowsky C, et al. From Mexico to Mali: progress in health policy and systems research. Lancet 2008;372:1571-8.

41 Hyder AA, Rattani A, Krubiner C, et al. Ethical review of health systems research in low- and middle-income countries: a conceptual exploration. Am J of Bioeth 2014;14:28-37.

42 Pratt B. Engagement as "co-constructing knowledge": A moral necessity in public health research. Bioeth2019.

43 Oswald K, Gaventa J, Leach M. Introduction: Interrogating engaged excellence in research. IDS Bull 2016;47:1-18.

44 Fricker M. Epistemic Injustice: Power and the Ethics of Knowing. Oxford University Press: Oxford, 2007.

45 Pratt B. Constructing citizen engagement in health research prioritysetting to attend to dynamics of power and difference. Dev World Bioeth 2018.

46 Pratt B. Inclusion of disadvantaged and marginalised groups in global health research priority-setting. J Empir Res Hum Res Ethics 2019;14:169-81.

47 Belsky L, Richardson HS. Medical researchers' ancillary clinical care responsibilities. BMJ 2004;328:1494-6.

48 Ostlin P, Braveman P, Dachs N, et al. Priorities for research to take forward the health equity policy agenda. Bull World Health Organ 2005;83:948-53.

49 Powers M, Faden R. Power Structural injustice: Advantage, and Human Rights. New York: Oxford University Press, 2019.

50 Powers M, Faden R. Social justice: The moral foundations of public health and health policy. New York: Oxford University Press, 2006.

51 Venkatapuram S. Health Justice: An Argument from the Capabilities Approach. Cambridge: Polity Press, 2011.

52 King $\mathrm{CH}$, Bertino A-M. Asymmetries of poverty: why global burden of disease valuations underestimate the burden of neglected tropical diseases. PLoS Negl Trop Dis 2008;2:e209.

53 Pratt B, Loff B. Linking research to global health equity: the contribution of product development partnerships to access to medicines and research capacity building. Am J Public Health 2013;103:1968-78.

54 Oxford Poverty and Human Development Initiative. OPHI country briefing June 2016: India, 2016. Available: http://www.ophi.org.uk [Accessed 1 Aug 2016]. 